\title{
Şanlıurfa Toplumundaki Erişkilerde Patella Tiplerinin Dağılımı ve Meniskal Rüptür İlişkisi
}

\section{Distribution of Patella Types and the Relationship Between Meniscal Rupture in Adults in Sanliurfa Society}

\author{
Kudret Cem KARAYOL 1
}

1. Harran Üniversitesi Tıp Fakültesi Fiziksel Tıp ve Reahbilitasyon Anabilim Dalı, Şanlıurfa, Türkiye

Öz.

Amaç: Patella tiplerindeki farklılıkların, menisküs üzerindeki yükü değiştirerek ve yürüme mekaniğinde değişikliğe neden olarak menisküs rüptürünün etiyolojisinde rol oynayabileceğini düşünüyoruz. Bu çalışmada patella tiplerinin dağılımı ve menisküs rüptürü ile ilişkisi araştırıldı.

Materyal ve Metod: Bu çalışmada, Ocak 2017- Temmuz 2018 tarihleri arasında Fizik Tedavi ve Rehabilitasyon polikliniğine başvuran 510 hastanın diz manyetik rezonans (MR) incelemeleri patella tiplerinin ayııımı ve menisküs rüptürünün dağılımı açısından PACS sisteminde retrospektif olarak tekrar değerlendirildi. Hastaların klinik öyküleri, muayene bulguları, yaşları ve cinsiyetleri hastanenin kayıt sisteminden alındı. On sekiz yaş alıındaki hastalar, majör travma öyküsü olan ve ameliyat edilen hastalar çalışma dışı bırakıldı. Diz MR incelemesi 3-Tesla magnet gücüne sahip MR cihazı (MagnetomSkyra, Siemens Healthcare, Erlangen, Almanya) ile standart diz koili kullanılarak gerçekleştirildi. Patella tipi sınıflamasında aksiyel PD görüntüleri kullanılarak, Baumgartl ve arkadaşlarının yaptıkları sınıflama esas alındı. Buna göre; Tip I: İçbükey ve eşit uzunluktaki medial ve lateral fasetler. Tip II: Medial faset düz veya içbükeydir, lateral faset medial fasetten daha belirgindir. Tip III: Daha küçük medial faset mevcut ve dışbükeydir. Tip IV: Medial faset veya merkez kenarı yoktur, jokey şapkası olarak adlandırıır. Elde edilen sayısal veriler, yaş, cinsiyet patella tipi ve menisküs yırtılması açısından SPSS 20.0 (SPSSInc., Chicago IL, USA) versiyonu istatistik paket programı kullanılarak işlendi.

Bulgular: Çalışmaya alınan $238(\% 46,7)$ kadın, $272(\% 53,3)$ erkek toplam 510 hasta, patella tipi ve menisküs rüptürü açısından değerlendirildi. Hastaların ortalama yaşları $38.83 \pm 0.5$ idi (en az 18, en çok 76). Tüm hastalarda Tip I patella 132 (\%25,9) Tip II 354 $(\% 69,4)$ Tip III $24(\% 4,7)$ olarak bulundu. 376 hastada, \%73,7 oranında menisküs yırtılması tespit edilmedi ve $134(\% 26,3)$ hastada menisküs yırtıması vardı. Menisküs yırtığı olan hastaların 68'i (\%50,7) kadın, 66'sı $(\% 49,3)$ erkekti.

Sonuç: Farklı patella tiplerinde simetrik ve simetrik olmayan yükleme sonucu menisküs üzerindeki orantısız veya simetrik olmayan basınç sonucu menisküs rüptürü eğiliminin artacağını düşündük. Ancak çalışmamızda meniskal rüptür ile patella tipleri arasında istatistiksel olarak anlamlı bir ilişki bulamadık.

Anahtar Kelimeler: Patella tipi, Menisküs yırtığı, Manyetik rezonans görüntüleme

\section{Abstract}

Background: We think that differences in patella types may play a role in the etiology of meniscus rupture by changing the load on the meniscus and causing changes in gait mechanics. In this study, we investigated the distribution of patella types and their relationship with meniscus rupture.

Materials and Methods: In this study, the knee magnetic resonance (MR) examinations of 510 patients admitted to the Physical Therapy and Rehabilitation outpatient clinic between January 2017 and July 2018 were re-evaluated retrospectively in the PACS system for the differentiation of patella types and the distribution of meniscus rupture. Clinical history, examination findings, age and sex of the patients were obtained from the hospital's registry. Patients under 18 years of age, patients with a history of major trauma and surgery were excluded.

Knee MRI was performed using a 3-Tesla magnet power MRI (MagnetomSkyra, Siemens Healthcare, Erlangen, Germany) using a Standard knee coil. Patella type classification was based on axial PD images and Baumgartl et al. According to this; Type I: Concave and equal length medial and lateral facets. Type II: Th emedial facet is flator concave, with the later alfacet more prominent than the medialfacet. Type III: Smaller medialfacet is presentand convex. Type IV: There is no medial facetorcenteredge, called jockey hat. The numerical data were analyzed using SPSS version 20.0 (SPSSInc., Chicago IL, USA) statistical package program for ge, sex patella type and meniscus rupture.

Results: A total of 510 patients (238 (46.7\%) female and $272(53.3 \%)$ male) were evaluated for patella type and meniscus rupture. The meanage of thepatientswas $38.83 \pm 0.5$ (minimum 18, maximum 76). Type I patella was found to be $132(25.9 \%)$ Type II 354 (69.4\%) Type III $24(4.7 \%)$ in all patients. In 376 patients, $73.7 \%$ had no meniscus rupture and 134 (26.3\%) had meniscus rupture. $68(50.7 \%)$ of the meniscus tear were female and $66(49.3 \%)$ were male.

Conclusion: We thought that in different patella types, the tendency of meniscus rupture would increase as a result of disproportionateor asymmetric pressure on the meniscus as a result of symmetrical and asymmetrical loading. However, we could not find a statisticallysignificant relationship between meniscal rupture and patella types.

Keywords: Patella type, Meniscustear, Magnetic resonance imaging

\section{Sorumlu Yazar I \\ Corresponding Author}

Kudret Cem KARAYOL

Harran Üniversitesi Tıp Fakültesi

Fiziksel Tıp ve Rehabilitasyon Anabilim

Dalı, Şanlıurfa, Türkiye

Osmanbey Kampüsü

Mardin Yolu $22 \mathrm{Km}$

63000 ŞANLIURFA

Tel: 05053700069

Tel: +90 4143183000

Fax: (0414) 3183192

E-mail: kudretcemkarayol@hotmail.com

Geliş tarihi / Received: 21.10.2019

Kabul tarihi / Accepted: 13.11.2019

\section{DOI: 10.35440/hutfd.634456}

Bu çalışma bir ön çalışma olarak 6-7 Nisan 2018 tarihlerinde Şanlıurfa'da yapılan, 5. Ulusal Harran Ortopedi günlerinde sözlü sunum olarak sunulmuştur.

Bu çalışma Harran üniversitesi Tıp Fakültesi Fiziksel Tıp ve Rehabilitasyon Anabilim dalında gerçekleştirilmiştir. 


\section{Giriş}

Patella vücuttaki en büyük sesamoid kemik olup kuadriseps tendonu ile patellar tendon arasında bulunur. Patella eklem yüzeyi medial ve lateral fasetlere ayrilır (1). Patella, femoral anterior sulkus ile eklem yaparak patellofemoral eklemi oluşturur (2). Diz hareketi sırasında patella femoral kondile göre hareket eder ve böylece biyomekanik bir işleve sahiptir (3). Patella diz fleksiyonunun ilk 90 derecesinde femoral sulkus ile eklemleşir, sonrasında medial ve lateral eklem yüzeyleri ile femoral kondillerle ayrı ayrı eklemleşir, fakat hareket sırasında hiçbir zaman femur ile tam temasa geçmez (1).

Menisküs, yarımay şeklinde fibro-kıkırdaktan oluşan bir yapıdır. Temel işlevi vücudun torsiyon ve basma kuvvetlerini alt ekstremiteye dağıtmak, şoku emmek ve sinovyal sıvıyı eklem yüzeyine dağıtmaktır (4). Menisküs yırtıkları travmatik, dejeneratif veya konjenital olabilir. Bununla birlikte, normal menisküse olan aşırı yükler veya dejeneratif menisküsün normal yüklemelerinin bir sonucu olarak direnç limitinin sonundaki normal bir menisküs de yırtılabilir (5). Yürüme sırasında, gövde kısa süreli bir düşüş göstermektedir. Bu, ön bacak üzerinde vücut ağırlığının\% 60'ının ve 0.02 saniyenin anormal şekilde yüklenmesine yol açar. Bu ayak bileği, diz ve kalçadaki şok emilim tepkisi ile azalır (6). Patella tiplerindeki farklılıkların, menisküs üzerindeki yükü değiştirerek ve yürüme mekaniğinde değişikliğe neden olarak menisküs rüptürünün etiyolojisinde rol oynayabileceğini düşünüyoruz. Bu çalışmada patella tiplerinin dağılımı ve menisküs rüptürü ile ilişkisi araştırıldı.

\section{Materyal ve Metot}

Bu çalışmada, Ocak 2017 - Temmuz 2018 tarihleri arasında Fizik Tedavi ve Rehabilitasyon polikliniğine başvuran 510 hastanın diz manyetik rezonans (MR) incelemeleri patella tiplerinin ayırımı ve menisküs rüptürünün dağılımı açısından PACS sisteminde retrospektif olarak tekrar değerlendirildi. Hastaların klinik öyküleri, muayene bulguları, yaşları ve cinsiyetleri hastanenin kayıt sisteminden alındı. Bu hastaların fizik muayenesinde Mc-Murray ve Aplay testleri pozitif bulundu. Onsekiz yaş altındaki hastalar, major travma öyküsü olan ve ameliyat edilen hastalar çalışma dışı bırakıldı. Ayrıca teknik olarak patelanın değerlendirilemediği vakalar da çalışmaya alınmadı.

Diz MR incelemesi 3-Tesla magnet gücüne sahip MR cihazı (Magnetom Skyra, Siemens Healthcare, Erlangen, Almanya) ile standart diz koili kullanılarak gerçekleştirildi. Yatar pozisyonda, diz hafif fleksiyonla diz koil içine yerleştirildi. Radyoloji kliniğinde kullanılan rutin diz MR sekansları aksiyal, sagital ve koronal yağ basılmış proton yoğunluğu (PD) ve sagital T1 sekansları elde edildi. Patella tipini belirlemede kullanılan aksiyel yağ baskılı T2 TSE görüntüler ve diğer bütün sekanslar hastaların tümünde aynı parametrelerle elde olundu.
Patella tipi sınıflamasında aksiyel PD görüntüleri kullanılarak Baumgartl ve arkadaşlarının yaptıkları sınıflama esas alındı (7). Buna göre; Tip I: İçbükey ve eşit uzunluktaki medial ve lateral fasetler (Şekil 1). Tip II: Medial faset düz veya içbükeydir, lateral faset medial fasetten daha belirgindir (Şekil 2). Tip III: Daha küçük medial faset mevcut ve dışbükeydir (Şekil 3). Tip IV: Medial faset veya merkez kenarı yoktur, jokey şapkası olarak adlandırıır (7).

\section{İstatistiksel analiz;}

Elde edilen sayısal veriler, yaş, cinsiyet patella tipi ve menisküs yırtılması açısından SPSS 20.0 (SPSSInc., Chicago IL, USA) versiyonu istatistik paket programı kullanılarak işlendi. Verilerin yaş ve cinsiyet dağılımı KiKare testiyle değerlendirildi. Normal dağılım gösteren sayısal veriler One-Sample Kolmogorov-Smirnov testi ile ve bunların ikili grup karşılaştırmaları da Student-t testi kullanılarak yapıldı. Üç veya daha fazla grubun karşılaştırılması için One Way ANOVA testi kullanıldı. Post Hoc LSD kullanılarak grup içi karşılaştırma yapıldı. İstatistiksel anlamlıık düzeyi $p<0.05$ olarak belirlendi..

\section{Bulgular}

Çalışmaya alınan 238 (\% 46,7) kadın, 272 (\% 53,3) erkek toplam 510 hasta, patella tipi ve menisküs rüptürü açısından değerlendirildi. Hastaların ortalama yaşları $38.83 \pm$ 0.5 idi (en az 18, en çok 76). Tüm hastalarda Tip I patella $132(\%$ 25,9) Tip II $354(\%$ 69,4) Tip III $24(\%$ 4,7) olarak bulundu. Çalışmaya alınan hastaların hiçbirinde tip IV patellaya rastlamadık (Tablo 1).

Tablo 1. Patella tiplerinin dağılımı

\begin{tabular}{lll}
\hline & Patella sayısı & Yüzde(\%) \\
\hline Tip I & 132 & $\% 25,9$ \\
Tip II & 354 & $\% 69,4$ \\
Tip III & 24 & $\% 4,7$ \\
Tip IV & 0 & $\% 0$ \\
Toplam & 510 & $\% 100$ \\
\hline
\end{tabular}

Tip I patellası olan hastaların 64 tanesi $(\% 48,5)$ kadın, 68 tanesi $(\% 51,5)$ erkekti. 165 kadın hasta $(\% 46,6)$ ve 189 $(\% 53,4)$ erkek hasta Tip II patellaya sahipti. Tip III patellası olan hastaları 9 tanesi $(\% 37,5)$ kadın ve 15 tensi $(\% 62,5)$ erkekti. Çalışmaya alınan tüm kadınların\% 26.9'u tip I, \% 69.3'ü Tip II, \% 3.8'i Tip III patellaya, tüm erkeklerin \% 25'i Tip I, \% 69.5'i Tip II ve \% 5.5'i Tip III idi. 376 hastada,\% 73,7 oranında menisküs yırtılması tespit edilmedi ve $134(\% 26,3)$ hastada menisküs yırtıması vardı (Grafik 1). Menisküs yırtığı olan hastaların 68'i $(\% 50,7)$ kadın, 66'sı (\% 49,3) erkekti. 


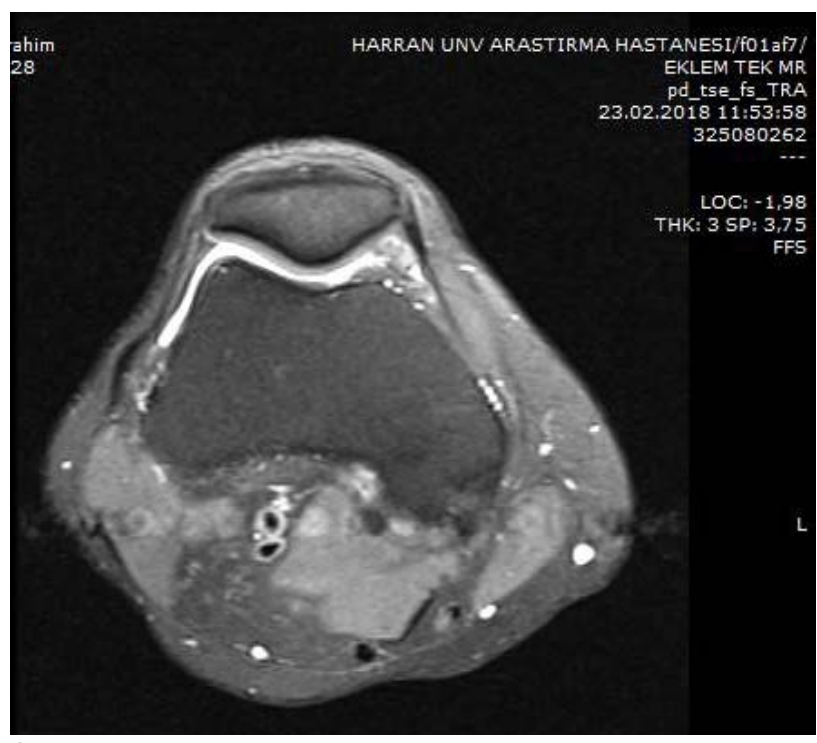

Şekil 1. Aksiyel proton dansite MR görüntüsü; Tip I Patella

\section{Tartışma}

MRG, kas iskelet sisteminde çok kanallı görüntü alma, yumuşak dokuları gösterme ve yüksek çözünürlük kabiliyeti nedeniyle yaygın kullanılan bir yöntemdir. Diz eklemi MRG'nin amacı genellikle eklemi oluşturan kemik yapılarını, kıkırdakları, bağları, tendonları ve menisküsleri değerlendirmektir. Patella aksiyal görüntülerde değerlendirilerek patella tipi söylenebilir, menisküs ise sagital ve koronal görüntülerde değerlendirilebilir (8).

Grafik 1. Patella tipi ile meniskal rüptür ilişkisi

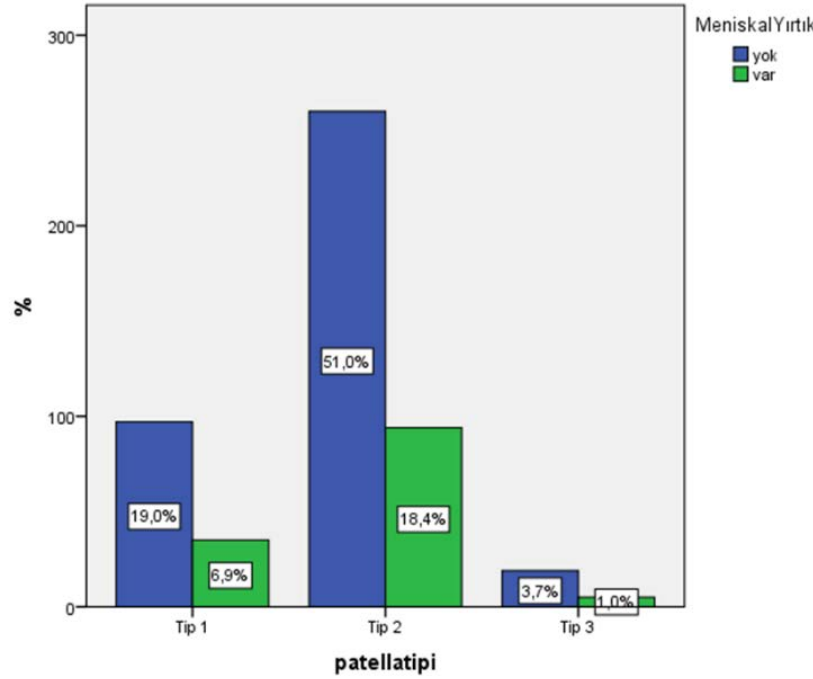

Shutzer ve arkadaşları patella boyutlarının çevre yumuşak dokuların çekimlerine direkt olarak bağlı olmadığını deneysel olarak göstermişler ve böylece patella tipinin bireysel farklııklardan etkilendiği düşünülmüştür. Küçük patellanın konjenital olarak çıkık olması veya cerrahi ile redükte edilememesi bunu kanıtlar niteliktedir (9). HeuterVolkman kanununa göre büyüme-gelişme çağındaki patellada kompresyon epifizyal büyümeyi geciktirir, traksiyon ise uyarır (10). Patella üzerindeki stres patellanın şeklini belirler ve tip I patellada simetrik bir yük varken, diğer tiplerde patella femoral sulkusta kayar (11). Biz bu özellik nedeniyle farklı patella tiplerinde vücut ağırlığının menisküsler üzerinde simetrik dağılamayacağını ve bu durumun aşırı yüklenme ile menisküs rüptüründe rol oynayabileceğini düşündük.

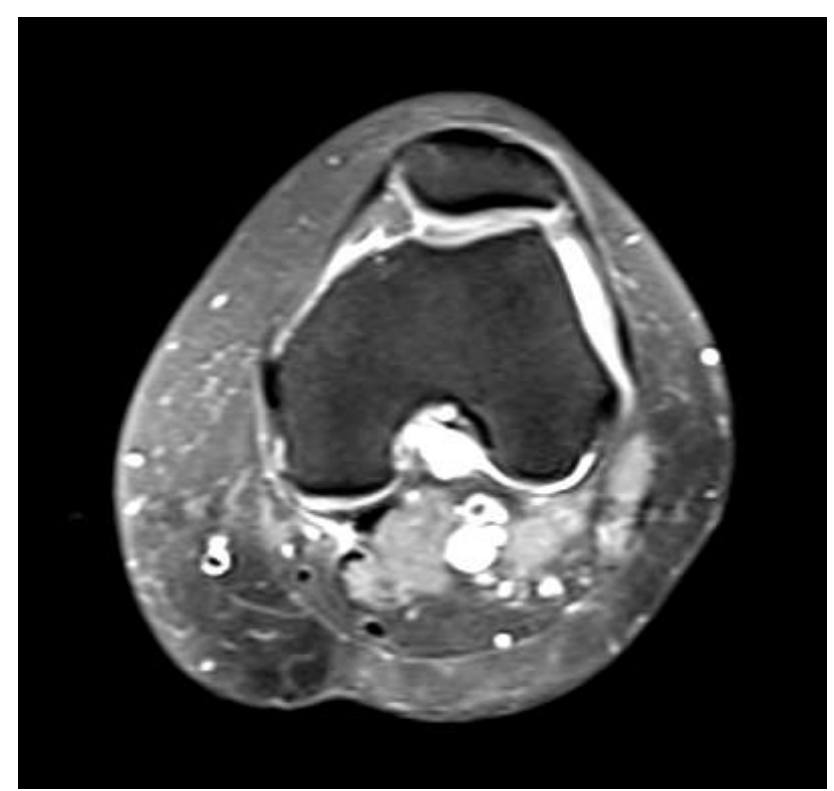

Şekil 2. Aksiyel proton dansite MR görüntüsü; Tip II Patella



Şekil 3. Aksiyel proton dansite MR görüntüsü; Tip III Patella

Rieder ve arkadaşları yaptıkları çalışmalarında sırasıyla tip II patellayı ( $\% 57)$ ve tip I patellayı (\% 24) ve Tip III patellayı (\% 19) oranında saptamışlardır(12). Kaplan ve arkadaşları Sakarya ilindeki erişkinlerde yaptıkları çalışmalarında Tip II patellayı \% 70, tip I patellayı \% 24 ve tip III patellayı \% 6 olarak bulmuşlardır(10). 1804 hasta ile yaptıkları çalışmada Arslan ve ark. tip II patellayı \% 42, tip III patellayı ve\% 36 tip I patellayı \% 19 ve tip IV patellayı 
$\% 4$ oranında saptadılar (13). Literatüre benzer şekilde bizde çalışmamızda en yaygın tip olarak Tip II patella tipini bulduk, daha sonra da sıklık sırasıyla tip I ve tip III patellalarını saptadık. Ancak literatürde patella tipi ile meniskal rüptür ilişkisini konu alan herhangi bir makaleye rastlayamadık.

Farklı patella tiplerinde simetrik ve simetrik olmayan yükleme sonucu menisküs üzerindeki orantısız veya simetrik olmayan basınç sonucu menisküs rüptürü eğiliminin artacağını düşündük. Ancak çalışmamızda meniskal rüptür ile patella tipleri arasında istatistiksel olarak anlamlı bir ilişki bulamadık $(p=0,825)$.

Çalışmamızın sınırıııkları, MRG'nin menisküs rüptürü için altın standart olmaması ve hastalarımızın yaş dağıımının farklı olmasıydı. Bu konuda benzer yaş dağılımında, daha büyük çalışma populasyonuyla ve artroskopik korelasyonla yapılacak çalışmaların katkı sağlayacağını düşünüyoruz.

\section{Kaynaklar}

1- Arnoczky SP: Anatomy of the anterior cruciate ligament. Clin Orthop. 1983; 172: 19.

2- Tria AJ, Palumbo RC, Alicea JA. Conservative care for patellofemoral pain. Orthop Clin North Am. 1992; 23: 545-55.

3- Dirik Y. Varus gonartrozunun tedavisinde medial kama açma tekniği ile yüksek tibial osteotomi uygulamalarımız ve sonuçlarımız. Uzmanlık tezi, S.B. Şişli Etfal Eğitim ve Araştırma Hastanesi 2. Ortopedi ve Travmatoloji Kliniği. İstanbul 2005.

4- Sanal HT. Diz Eklemi: Menisküs ve Bağlar, TRD Sem 2016; 4:439-52d DOI: $10.5152 /$ trs. 2016.418

5- B. Alparslan, E. Çullu. Menisküs yaralanmaları ve cerrahi tedavileri. Adnan Menderes Üniversitesi Tıp Fakültesi Dergisi. 2000; 1(1):47-55

6- Perry J. Gait Analysis: Normal and Pathological Function. Thorofare, NJ: SLACK Incorporated; 1992

7- Baumgartle F. Das Kniegelenk: Berlin, Springer-Verlag, 1964

8- Arkun R. Imaging of articular cartilage. Acta Orthop Traumatol Turc. 2007;41:32-42.

9- Schutzer SF, Ramsby GR, Fulkerson JP. Computer tomographic classification of patellofemoral pain patients. Orthop Clin North Am. 1986; 17: 235-48.

10- Kaplan T, Başar H, İnanmaz ME. Sakarya ilindeki Erişsinlerde Patella Tiplerinin Dağlımı. Sakarya Medical Journal. 2014;4(3):125-128.

11- Aglietti $P$, Buzzi R, Insall JN. Disorders of the patellofemoral joint. In: Insall JN, Scott WN. Ed. 3th edition. Surgery of the knee. New York: Churchill Livingstone, 2001: 913-959.

12- Reider B, Marshall JL, Koslin B. The anterior aspect of the knee joint an anatomic study. J Bone Joint Surg. 1981; 63-A: 351-6.

13- Arslan E, Acar T, Adibelli ZH.. Türk toplumunda patellar kondromalazi: prevalansı ve patella tipleri ile olan ilişkisi. Tepecik Eğit ve Araşt. Hast. Dergisi 2018; 28 (2): 83-8 